\title{
Laboreal
}

Volume $17 \mathrm{~N}^{\circ} 1$ | 2021

Trabalhar hoje: mudanças, permanências, estratégias, reinvenções

\section{Gestión del trabajo y de la salud pública en tiempos de pandemia}

Gestões do trabalho e da saúde pública em tempos de pandemia

Jussara Brito, Letícia Pessoa Masson y Marcelo Gonçalves Figueiredo

Traductor. Fernanda Romero (fernandaromero.trad@gmail.com)

\section{(2) OpenEdition}

Edición electrónica

URL: https://journals.openedition.org/laboreal/17554

DOI: $10.4000 /$ laboreal. 17554

ISSN: 1646-5237

\section{Editor}

Universidade do Porto

Referencia electrónica

Jussara Brito, Letícia Pessoa Masson y Marcelo Gonçalves Figueiredo, «Gestión del trabajo y de la salud pública en tiempos de pandemia», Laboreal [En línea], Volume 17 № 1 | 2021, Publicado el 18 junio 2021, consultado el 20 junio 2021. URL: http://journals.openedition.org/laboreal/17554 ; DOI: https://doi.org/10.4000/laboreal.17554

Este documento fue generado automáticamente el 20 junio 2021.

Laboreal está licenciado com uma Licença Creative Commons - Atribuição-NãoComercial 4.0 Internacional. 


\title{
Gestión del trabajo y de la salud pública en tiempos de pandemia
}

\author{
Gestões do trabalho e da saúde pública em tempos de pandemia \\ Jussara Brito, Letícia Pessoa Masson y Marcelo Gonçalves Figueiredo \\ Tradución : Fernanda Romero (fernandaromero.trad@gmail.com)
}

1 En el texto de presentación de la Efeméride del número anterior, Liliana Cunha pone de relieve que el alcance de todo el devenir histórico de la pandemia de Covid-19 sigue abierto y propone las siguientes reflexiones: ¿Qué historia podemos/queremos construir? ¿Cuál el lugar y qué encuentros con el trabajo nos reserva esta historia? Preguntas tan necesarias e instigadoras que sólo las podremos responder, a nuestro juicio, desde miradas complementarias y atentas a las cuestiones que atraviesan la vida en el trabajo. Es en este sentido que en la Efeméride de esta adición buscamos dar continuidad a la reflexión iniciada en los textos de diciembre de 2020, centrándonos ahora, en particular, en la realidad brasileña y en las formas en que el trabajo y la salud pública vienen siendo abordados, gestionados y encaminados en el país durante la pandemia.

2 El primero artículo de este dosier, de la autoría de Sandra Caponi, hace un importante registro sobre el trágico "marzo de 2021", cuando se cumplía un año de la pandemia y, en Brasil, ya se habían producido más de 300 mil muertes por Covid-19. A partir de las aportaciones de Foucault, encontramos en su texto materiales fértiles para comprender como se articulan las estrategias del gobierno para gestionar la pandemia con los saberes, discursos y enunciados científicos. Un análisis que nos remite a la esfera del trabajo, cuando cuestiona la falsa dicotomía entre la defensa de la vida e la defensa de la economía, como si representaran intereses enmarcados en polos antagónicos, al tratar el negacionismo científico. Así, específicamente en Brasil, se presentan discursos que niegan las evidencias científicas a respecto de la gravedad del cuadro de contagio, enfermedad y muerte, para que ciertas actividades de trabajo presenciales no sean interrumpidas. Dicha postura pone en peligro las vidas de los que son obligados a desplazarse diariamente de sus casas a los locales de trabajo, en medios de transporte público siempre abarrotados, como los autobuses, los trenes y las furgonetas. La situación se vuelve aún más crítica al no implementarse las medidas necesarias para 
controlar la pandemia, como el apoyo económico a los trabajadores para que puedan cumplir el aislamiento social.

3 Sus argumentos indican que la exposición sistemática de individuos y de grupos a muertes evitables puede caracterizarse como una gestión necropolítica de la pandemia. Con su aportación, Caponi coloca el enfoque en el tema de los derechos humanos - que no está disociado de la cuestión del negacionismo científico en la medida en que la negación de los saberes producidos en el ámbito de la ciencia representa un obstáculo al derecho a la verdad.

4 Al traer el ejemplo de Nueva Zelandia, como contrapunto al caso brasileño, Caponi se adentra en otras cuestiones referentes a la gestión de la pandemia que también afectan al mundo del trabajo, haciendo hincapié en las diferentes consignas que atraviesan las biopolíticas adoptadas por los dos países (por un lado, la solidaridad colectiva, y, por otro, la responsabilización individual por el control de los riesgos de infección). Sí, la solidaridad colectiva, como un valor sin dimensión (Schwartz, 2000), se reflejará en los medios de trabajo, bien como su ausencia (y el énfasis en los valores del mercado) dejará marcas en el cuerpo de los trabajadores.

5 A continuación, tenemos la aportación de Ana Cláudia Barbosa da Silva-Roosli, cuyo texto coloca el enfoque en la fecha en que la pandemia de Covid fue reconocida por la Organización Mundial de la Salud -"11 de marzo de 2020"- con reflexiones sobre su enfrentamiento por los servicios (y trabajadores) de salud. Su lectura propicia, especialmente, una mirada al trabajo en la Atención Primaria de Salud (APS) en Brasil, advirtiendo que sus potencialidades han sido desperdiciadas. No se trata sólo de destacar sus atribuciones, sino de poner de relieve la diversidad de respuestas dadas por los trabajadores vinculados a la APS a las numerosas cuestiones planteadas por la pandemia en los distintos territorios, en particular las iniciativas del equipo multidisciplinar de la Estrategia de Salud Familiar. Llama la atención para las relaciones de servicio (Zarifian, 2001) establecidas en el desarrollo de sus actividades, teniendo en cuenta que las acciones de salud no pueden ser totalmente anticipadas, concretizándose de una manera privilegiada en el encuentro (imprescriptible) con los usuarios del sistema.

6 Los interesantes ejemplos de formas de reorganizar el trabajo sanitario en la APS evidencian el protagonismo de los trabajadores directamente involucrados en las actividades de cuidados, incluso de personas con sospecha de Covid-19, en la creación de distintas estrategias para garantizar la atención a los usuarios e incluso para reducir el nivel de propagación de la enfermedad. Entre las estrategias indicadas por la autora, podemos mencionar, ya en esta breve introducción, la utilización de los medios de comunicación social con el fin de combatir la circulación de noticias falsas sobre la enfermedad (vinculadas al negacionismo explorado en el texto de Caponi), así como para proporcionar orientaciones a los usuarios en riesgo de Covid-19.

7 La autora también nos llama a reflexionar sobre las potencialidades que encierra el trabajo de los Agentes Comunitarios de Salud para el control de la pandemia, teniendo en cuenta su capacidad de movilización social que resulta de la proximidad a las comunidades donde actúan.

8 Entendemos que el artículo de Silva-Roosli representa una invitación para mirar con atención las experiencias que se están desarrollando y para los saberes que se están instituyendo en los servicios de salud frente al actual contexto de crisis sanitaria, lo que 
implica cambios significativos en sus procesos de trabajo y en la construcción de un patrimonio colectivo.

El tercer texto, de Élida Hennington, versa sobre el "28 de abril", instituido en 2003 como el "Día mundial en memoria de las víctimas de accidentes de trabajo y enfermedades profesionales". Una efeméride reciente y poco conocida en el universo laboral si se compara al $1^{\circ}$ de Mayo, referencia internacionalmente consagrada y que remonta al siglo XIX.

Sin embargo, la propagación del nuevo coronavirus por el planeta y sus repercusiones en el ámbito laboral tienden a dar nuevos contornos a la fecha. La dimensión de la catástrofe sanitaria, con sus millones de muertes y graves secuelas, ha impuesto un esfuerzo de excepcional envergadura, tanto para enfrentar el virus como en el aprendizaje relacionado con este a lo largo de la subsiguiente lucha sin precedentes a escala mundial.

11 De conformidad con la autora, la evolución de la pandemia en el mundo no hizo más que reforzar el motivo por el cual la salud y la seguridad se deben consolidar como un derecho de todos los que trabajan. Una de las señales de alarma más contundentes procede de los brotes de Covid-19 en diferentes categorías profesionales y en distintos procesos y locales de trabajo, así como del creciente número de enfermedades y muertes de trabajadores, sobre todo de los que trabajan en la llamada primera línea y se consideran "esenciales", pero no sólo estos.

En este sentido, todo el esfuerzo por reconocer la Covid-19 como una enfermedad profesional puede considerarse una significativa contribución más a la historia de las luchas por unas mejores condiciones de vida y de trabajo. Como señala Hennington, no obstante la evidencia científica de que el Sars-Cov-2 causa la Covid-19, en numerosos casos es difícil comprobar la exposición laboral, o incluso que la patología se adquirió como consecuencia del trabajo, dada la presencia del virus no sólo en el entorno laboral, sino también fuera de él.

Además, cabe también resaltar que el citado texto trae como epígrafe en su subtítulo "¿qué aprender con la Covid-19?". Y esta indagación evoca algo que nos parece ineludible cuando se trata de salud y seguridad, además del mundo del trabajo, a nivel mundial. Como sostienen algunos científicos de renombre, a partir de ahora tenemos que estar preparados para otros eventos catastróficos, como la pandemia de la Covid-19, y no debemos subestimar los riesgos de nuevas catástrofes mundiales.

14 Esperamos que la lectura de los textos de esta Efeméride contribuya para la reflexiónacción tanto sobre el local de trabajo en la historia de esta pandemia, como sobre su relación con las acciones de salud pública, según las provocaciones de Liliana Cunha (2020). Si bien es cierto que hablar en el presente del complejo y desalentador momento que vivimos se revela un limitador de la mirada por la falta de perspectiva importante para la profundización de los análisis, este examen se plantea de forma urgente, en la medida en que se relaciona con la defensa de la vida. En este sentido, por ejemplo, es necesario registrar la más grave de las numerosas estadísticas nefastas de Brasil: en nuestro país más de la mitad de la población no se ha alimentado como debería, o ya tenía algún tipo de incertidumbre respecto a la alimentación en el futuro durante la pandemia de coronavirus [1].

15 Así, la búsqueda de dar visibilidad al trabajo debe ir más allá de la relativa expansión que el debate sobre ciertas ocupaciones ha alcanzado desde la pandemia. Se trata, más 
bien, de pleitear que esta visibilidad se convierta en cambios efectivos en las nocividades que experimentan cotidianamente los trabajadores y las trabajadoras. Puesto que, si de alguna manera el trabajo ha tenido destaque en el debate público sobre el Bien Común, como, por ejemplo, un incremento de la valorización social del SUS (Sistema Único de Salud) o la emergencia de movimientos de trabajadores basados en aplicaciones (el "Breque dos Apps"), la precariedad de las condiciones de vida y de trabajo se ha agravado.

\section{BIBLIOGRAFÍA}

Cunha, L. (2020). Pandemias e (des)encontros com o trabalho. Laboreal, 16(2). https://doi.org/ 10.4000/laboreal.17408

Schwartz, Y. (2000). Le paradigm ergologique ou un métier de philosophe. Toulouse: Octares.

Zarifian, P. (2001). Objetivo competência. Por uma nova lógica. São Paulo: Atlas.

\section{NOTAS}

1. Fuente: https:// www.brasildefato.com.br/2021/04/13/brasil-tem-125-6-milhoes-de-pessoasem-situacao-de-inseguranca-alimentar-na-pandemia. Investigación "Efectos de la pandemia en la alimentación y la situación de la seguridad alimentaria en Brasil”, coordenada por el Grupo de Investigación Alimento para la Justicia de la Universidad Libre de Berlín, Alemania, en asociación con la Universidad Federal de Minas Gerais (UFMG) y la Universidad de Brasilia (UnB).

\section{AUTORES}

\section{JUSSARA BRITO}

https://orcid.org/0000-0001-6744-4595

Fundação Oswaldo Cruz, Rua Leopoldo Bulhões, 1480 - Manguinhos, 21041-210, Rio de Janeiro -

RJ, Brasil

jussara@ensp.fiocruz.br

\section{LETÍCIA PESSOA MASSON}

http://orcid.org/0000-0002-5422-286X

Escola Nacional de Saúde Pública da Fundação Oswaldo Cruz (ENSP/FIOCRUZ), Rua Leopoldo

Bulhões, 1480 - Manguinhos, 21041-210, Rio de Janeiro - RJ, Brasil

leticiamasson@ensp.fiocruz.br 


\section{MARCELO GONÇALVES FIGUEIREDO}

https://orcid.org/0000-0001-5612-2929

Departamento de Engenharia de Produção da Universidade Federal Fluminense (UFF), Rua Passo da Pátria, 156 - São Domingos, 24210-240, Niterói - RJ, Brasil

marceloparada@uol.com.br 